\title{
Learner interaction in a massively multiplayer online role playing game (MMORPG): A sociocultural discourse analysis
}

\author{
AUTHOR(S): \\ Peterson, Mark
}

\section{CITATION:}

Peterson, Mark. Learner interaction in a massively multiplayer online role playing game (MMORPG): A sociocultural discourse analysis. ReCALL 2012, 24(03): 361-380

\section{ISSUE DATE:}

2012-09-26

URL:

http://hdl.handle.net/2433/168065

\section{RIGHT:}

(C) Cambridge University Press 2012; 許諾条件により本文は2013-0927に公開. 


\title{
Learner interaction in a massively multiplayer online role playing game (MMORPG): A sociocultural discourse analysis*
}

\author{
MARK PETERSON \\ Graduate School of Human and Environmental Studies, Kyoto University, Yoshida- \\ Nihonmatsu-cho, Sakyo-ku, Kyoto 606-8501, Japan \\ (email: M.Peterson@fx8.ecs.kyoto-u.ac.jp)
}

\begin{abstract}
This exploratory study investigates the linguistic and social interaction of four intermediate EFL learners during game play in a massively multiplayer online role playing game (MMORPG). Twelve illustrative episodes drawn from the participants' text chat, collected in four 70-minute sessions held over a one-month period, are analyzed from a sociocultural perspective. Qualitative analysis reveals the presence of interactional features associated with the development of sociocultural competence. Throughout this study the learners successfully engaged in collaborative social interaction involving dialogue, conducted exclusively in the target language. Participants made appropriate use of politeness involving greetings, informal language, small talk, humor, and leave-takings, as a means to support the operation of collaborative interpersonal relationships. These relationships appeared based on reciprocity, friendship, and teamwork. They were effective in facilitating the creation of a low stress atmosphere characterized by social cohesion that was conducive to co-construction, and the consistent production of coherent target language output. The data indicates that the learners were able to jointly establish, and maintain, states of intersubjectivity through the use of continuers, and requests for assistance relevant to in-game tasks. Learner feedback was positive, and suggests that although the participants found the game play challenging, as this research progressed they became increasingly comfortable as their familiarity with the game increased. Aspects of participation identified by the learners as beneficial included opportunities for risk-taking, enhanced fluency practice, and exposure to vocabulary not normally encountered in regular language classes. The analysis suggests that the game provided access to an environment conducive to forms of collaborative target language use and social interaction identified as beneficial in the sociocultural account of language development.
\end{abstract}

Keywords: CMC, Gaming, MMORPG, CALL, sociocultural theory, interaction, SLA

\section{Introduction}

There has been increasing discussion in the CALL literature on the potential of participation in computer gaming as a means to facilitate language development

* This research was made possible by the generous support of the Hayao Nakayama foundation for science, technology, and culture. 
(Ang \& Zaphiris, 2006; Peterson, 2010b). Influenced by earlier work on the use of text and 3D-based virtual worlds such as MOOs and Second Life (Deutschmann, Panichi \& Molka-Danielsson, 2009; Warner, 2004) that facilitate real time computer mediated communication (henceforth $\mathrm{CMC}$ ), research has recently focused on a genre of network-based role-playing game known as a MMORPG (Zhao \& Lai, 2009). This effort has been inspired, in part, by the emergence of multiplayer gaming as a major worldwide social phenomenon (Peterson, 2010a; Thorne, Black \& Sykes, 2009). Another factor that has contributed to the interest in the potential of networkbased role playing games has been the growing influence of the account of second language acquisition (SLA) informed by sociocultural theory. This emphasizes the important role played by social interaction in the development of sociocultural competence necessary for language learning (Lafford, 2007). In recent years, these developments have led researchers to explore, in a limited number of studies, the use of network-based role-playing games in CALL (Peterson, 2011; Reinders \& Wattana, 2011; Suh, Kim \& Kim, 2010). This paper will first examine the development of MMORPGs and their most significant features. Then, from a perspective of SLA inspired by sociocultural research, the theoretical introduction discusses rationales identified in the literature that justify the use of MMORPGs in CALL, and provides an overview of the significant findings from related research and contemporary studies that focus on learner interaction in CMC settings. This is followed by a qualitative exploratory study that investigates the interactions and attitudes of four intermediate EFL learners in a MMORPG.

\subsection{MMORPGs: Significant features}

The development of MMORPGs was influenced by network-based desktop virtual reality systems known as MOOs (Peterson, 2010b). These object-oriented communication systems provide for purposeful real time text-based interaction within a persistent $2 \mathrm{D}$ virtual world. MOO virtual environments provide access to user created virtual spaces known as rooms that are based on a theme. Individual users have opportunities to create virtual objects and adopt unique online identities known as characters. In a $\mathrm{MOO}$ world, individual characters may utilize unique pseudonyms in order to undertake text chat, role play, and navigation, through the use of specific commands. More recently, accessibility was enhanced with the introduction of browser-based MOOs that utilize hypertext and this development significantly increased opportunities to interact with a wider range of users.

A further influence on the design of contemporary MMORPGs has come from 3D virtual worlds such as Active Worlds and Second Life. As Table 1 shows, such virtual worlds share a number of features with MOOs. For example, users can engage in real time text chat. There are also opportunities to create new worlds and virtual objects. However, designers have utilized technological advances to enhance the user experience. Contemporary virtual worlds incorporate persistent theme-based 3D simulated environments that are accessible through web browsers. These are of higher quality than those provided by most 2D MOOs. Immersion is facilitated by the availability of visually rendered digital avatars that enable players to communicate through text chat and gestures. Avatars may traverse virtual space through the use of 
Table 1 Significant features of MOOS, 3-D virtual worlds and MMORPGs

\begin{tabular}{|c|c|c|c|}
\hline Environment & MOOs & 3-D Virtual Worlds & MMORPGs \\
\hline Type of world & $\begin{array}{l}\text { Immersion in } 2 \mathrm{D} \text { user-created } \\
\text { virtual worlds based on a } \\
\text { theme }\end{array}$ & $\begin{array}{l}\text { Immersion in 3D user-created virtual worlds } \\
\text { based on a theme }\end{array}$ & $\begin{array}{l}\text { Immersion in high quality } 2 \mathrm{D} \text { or } \\
3 \mathrm{D} \text { virtual worlds based on a } \\
\text { theme or narrative }\end{array}$ \\
\hline Means of communication & $\begin{array}{l}\text { Communication through typed } \\
\text { text }\end{array}$ & Communication through text and voice chat & $\begin{array}{l}\text { Communication through text } \\
\text { and voice chat }\end{array}$ \\
\hline Type of characters & Text-based characters & User controlled avatars & User controlled avatars \\
\hline Type of environment & $\begin{array}{l}\text { Open communication } \\
\text { environment }\end{array}$ & Open communication environment & $\begin{array}{l}\text { Goal-based communication } \\
\text { environment. Successful quest } \\
\text { completion required for player } \\
\text { status enhancement and } \\
\text { progression }\end{array}$ \\
\hline Content creation & $\begin{array}{l}\text { Users can create new rooms } \\
\text { and virtual objects }\end{array}$ & $\begin{array}{l}\text { Users can create new worlds } \\
\text { and virtual objects }\end{array}$ & $\begin{array}{l}\text { Players can customize many } \\
\text { aspects of the game (modding) } \\
\text { Membership of game-based } \\
\text { social groups is available }\end{array}$ \\
\hline
\end{tabular}


mouse clicks and keyboard commands. The customizable nature of avatars has been found to enhance the degree of attachment and emotional investment experienced by users (Peterson, 2006). The presence of avatars provides opportunities for individual players to undertake character development and role play. In a further innovation, users are provided with access to audio communication tools.

The design of MMORPGs has drawn on the above innovations. Contemporary MMORPGs are based on a theme or narrative and present high quality graphical user interfaces that possess great visual appeal. In common with $3 \mathrm{D}$ virtual worlds, players are provided with user controlled customizable avatars and real time text and audio communication tools. MMORPGs offer opportunities to interact with non-player virtual agents that can supply real time assistance, and information on the requirements of in-game activities. In many MMORPGs, individual players can customize aspects of the game, an activity known as modding (Gee, 2005; Steinkuehler, 2008). Moreover, many of these games such as, for example, World of Warcraft can be played on a variety of mobile communication devices, including smart phones and tablet computers. This development has greatly increased the number of players to the extent that online gaming is now a global phenomenon.

As Table 1 shows, a major difference between MOOs, 3D virtual worlds, and MMORPGs, is that the latter are specifically designed to elicit purposeful interaction (Prensky, 2001; Purushotma, Thorne \& Wheatley, 2009). In order to progress in the game hierarchy, individual players are required to undertake goal directed in-game tasks known as quests. These can incorporate a wide range of activities including engaging in combat, solving puzzles, trading of virtual commodities, and the acquisition of game-specific skills such as healing or magic. Successful quest completion frequently involves collaboration with other players. In many MMORPGs this occurs under the auspices of game-based social organizations known as guilds. In guilds, novices can receive assistance, and advice from more experienced peers through linguistic interaction both in the game and in game-related chat rooms. Membership of guilds provides opportunities to develop social relationships based on common goals that enable individuals to engage in the teamwork and alliance building necessary to complete the increasingly complex quests required for status advancement in the game. Researchers have claimed that the combination of such features appear to make MMORPGs potentially valuable arenas for CALL (Sykes, Reinhardt \& Thorne, 2010). The following discussion explores some claims that have been made regarding the value of participation in MMORPGs for language learners, and then proceeds to examine some relevant related research in CMC.

\subsection{MMORPGs in CALL: rationales}

Researchers have proposed a number of theoretical justifications for the use of MMORPGs in language learning (Peterson, 2010a; Zhao \& Lai, 2009). Of these, conceptions of language learning that are informed by sociocultural theory have attracted increasing attention. Influenced by theories of human learning first proposed by Vygotsky (1978), this body of work (Firth \& Wagner, 2007, Lantolf \& Appel, 1994) from which this research draws, has evolved over the years and emphasizes the roles played by interaction, communication, collaboration, and zones of proximal development in 
language acquisition (Nassaji \& Swain, 2000). From the perspective of sociocultural SLA, language learning is facilitated by social interaction (Atkinson, 2002). Learning is viewed as transformational in nature; lower level mental functions such as attention and memory, are transformed to higher level functions such as planning and problem solving, through interaction with more capable peers (Lantolf, 2000). Central to this dynamic process is the concept of mediation (Wertsch, 2007). The transformation of mental functions is achieved through interaction involving the use of mediating tools such as language or computers. During interaction, learners and more capable peers engage in collaborative dialogue involving scaffolding. This type of interaction is viewed as central to the learning process, as it facilitates the operation of zones of proximal development (henceforth ZPD). These interactive states which have been identified in computer-based interaction (Lee, 2008), occur when learners are assisted by more capable peers in undertaking target language (henceforth TL) functions they could not complete unaided (Vygotsky, 1978). Participation in the co-construction of TL forms through collaborative dialogue involving assistance is further seen as leading to intersubjectivity, and ultimately to the development of self-regulation that is considered crucial for language learning (Lantolf \& Thorne, 2006).

Researchers emphasize the new opportunities MMORPGs present for motivating, challenging, and purposeful TL use and social interaction (Sykes, Reinhardt \& Thorne, 2010). They draw attention to the possibilities for intercultural interaction with native speaker and peers located in diverse geographic locations (Peterson, 2011). Moreover, they observe that successful quest completion frequently requires collaboration in the TL, membership of in-game social organizations known as guilds, and participation in game-related chat rooms (Thorne, 2008). These aspects of participation in game play frequently enhance the development of interpersonal relationships, common goals, and community formation. In a sociocultural account of SLA these factors are necessary for language socialization (Thorne, Black \& Sykes, 2009). In this view, by facilitating engaging social interaction in the TL, well-designed MMORPGs provide access to environments that may be conducive to the operation of states of intersubjectivity, zones of proximal development, and ultimately, the development of sociocultural competence and self-regulation (Thorne, 2008).

\subsection{Previous empirical research}

As was observed at an earlier stage of this discussion, research on the use of MMORPGs has been influenced by work on MOOs and 3D virtual worlds. The literature on the use of these environments in CALL projects draws attention to a number of possible benefits. Researchers have reported that regular interaction elicits TL use and collaborative dialogue involving behaviors associated with the development of sociocultural competence such as the provision of assistance and appropriate peer feedback (Deutschmann, Panichi \& Molka-Danielsson, 2009; Donaldson \& Kötter, 1999). Further beneficial aspects of interaction include opportunities for language play, enhanced engagement, intercultural awareness, and the formation of communities based on collaborative interpersonal relationships (Jauregi, Canto, de Graaf, Koenradd \& Moonen, 2011; Schwienhorst, 2002; Von Der Emde, Schneider \& Kötter, 2001; Warner, 2004). 
Although research that explores learner interaction in MMORPGs remains limited, a small number of experimental studies have been conducted. Reinders and Wattana (2011) investigated the use of a commercial MMORPG that had been adapted for use in second language education. The researchers found that participation in the game over three sessions elicited increases in the quantity of TL output. The data showed that the output contained a variety of discourse functions associated with social interaction including greetings, clarification requests, corrections, and questions. However, errors were frequent. Moreover, the complexity and accuracy of TL output did not improve. Analysis of feedback data indicated that the learner's willingness to communicate appeared to be enhanced by taking part in the game play.

Research reported by Suh, Kim and Kim (2010) explored the use of a MMORPG with elementary school students in Korea. This large scale study found that English students who utilized a MMORPG to engage in text chat and various in-game activities such as trading gained test scores in reading and writing higher than those of a control group that undertook regular classes and that did not participate in game play. The researchers claimed that learner performance was influenced by motivation and prior knowledge. They also noted that learner participation was negatively influenced by technical issues, in particular by network connection speeds.

A recent study undertaken by Peterson (2011) found that novice players experienced difficulties in managing communication systems. This factor, coupled to problems in utilizing game-specific commands, prevented the above learner group from engaging in beneficial types of interaction. This researcher reported that the majority of the participants utilized adaptive discourse management strategies along with strategies transferred from interaction in face-to-face contexts in order to successfully manage their TL interaction. These strategies included politeness, time saving, and feedback devices. The data showed that the learners who had prior experience of online gaming undertook collaborative dialogue conducted exclusively in the TL. Learner feedback was largely positive, with claims that participation in the game was enjoyable and provided exposure to new vocabulary. Several learners reported that they considered the TL practice valuable.

\subsection{Research questions}

The discussion in the previous section suggests that participation in MMORPGbased gaming, though challenging, may be beneficial in aspects considered crucial for language learning. However, as was noted previously research is at an early stage and many areas such as learner social interaction and attitudes remain in need of further investigation. In order to shed new light on the nature of EFL learner linguistic and social interaction in a MMORPG, and add to work in this area, this exploratory qualitative research investigates the following questions from a sociocultural perspective:

1. What are the significant features of EFL learner linguistic and social interaction in a MMORPG?

2. What are learner attitudes toward participation in MMORPG-based gaming? 


\section{Methodology}

\subsection{Participants}

The volunteer participants in this research were four EFL students based at a university in Japan. Responses to a pre-study questionnaire indicated that three of the students were female. Two learners were Japanese, while the others were from China and Iran. The learners ranged in age from 23 to 25 years old, and proficiency test scores indicated intermediate level English language proficiency. Although the students were experienced computer users, none of them claimed to have any prior experience of playing an English language MMORPG.

\subsection{Learning environment}

The design of the MMORPG utilized in this research, Wonderland (http://wl.igg.com/), is based on Japanese animation and manga themes. This free social game provides access to a high quality $2 \mathrm{D}$ world where individual players utilize avatars that can traverse virtual space in real time. The game adopts a story line in which players are shipwrecked on a desert island. In order to advance in status (level up), players are required to engage in a wide variety of quests and on achieving a certain status level have the opportunity to join guilds. The game provides access to an onscreen text chat tool, and hyperlinks designed to facilitate social interaction such as offering friendship. Players are also provided with a set of predesigned emoticons that, when selected, enable their avatar to display a range of emotional responses, and physical actions, in real time. This game was selected as the venue for this research as it provides a robust, and user-friendly, interface. Other beneficial design elements include the provision of a game website, extensive online player forums, and help resources.

\subsection{Data collection and analysis}

This study was conducted during the spring semester (April through July) 2011. Participants gave their written consent for the collection, analysis, and quotation of transcript data. Prior to data collection, the participants undertook an orientation session, in which they were introduced to the main concept, commands, and communication features of Wonderland. This was supplemented with the provision of information on the resources available online, including the help website and FAQ page. The participants then took part in four sessions held once a week over a period of one month. Each session lasted approximately seventy minutes. However, there were slight variations in the duration of each session due to occasional instances of lateness. The researcher, who acted as an observer, recorded the text chat produced in each of the sessions with screen capture software. On conclusion of the session, the researcher saved this data to a file for discourse analysis. In order to provide for anonymity in the data write up, all participants utilized a pseudonym. They were requested to use the same pseudonym in each session. To obtain a holistic perspective and facilitate triangulation, additional data sources were collected. Data was obtained from pre- and post-study questionnaires. On conclusion of the final session, personal interviews were conducted with each participant. 


\section{Findings and discussion}

The following twelve excerpts provide illustrative examples and descriptions of significant features of the participants' real-time linguistic and social interaction in Wonderland that occurred over the four weeks of this study. The discussion draws attention to the presence of constructs indentified as beneficial in the sociocultural account of language development. Individual participants and their interlocutors are identified by pseudonyms, such as, learner 1, and player 1 . All of the data has been provided as it occurred. Lines of text not relevant to the interaction such as automatically generated system messages are in parenthesis.

\subsection{Politeness: greetings}

In the computer-based interactional context provided by Wonderland, communication is carried out through typed text, and many of the auditory and social context cues that influence communication in face-to-face contexts such as intonation, age, and sex are either absent or reduced. Analysis revealed that the reduction of such cues may have led the participants to make extensive use of politeness (Brown \& Levinson, 1987). This was used as a means to facilitate social interaction and collaboration, and to reduce threats to face. As the following transcript data will show, the participants made appropriate use of a range of positive politeness strategies designed to build rapport, display sociability, and a desire to be part of the group.

One type of positive politeness that was a feature of the sessions, was the use of greetings. The literature on native speaker text chat emphasizes the importance of greetings in signaling presence, gaining attention, and establishing a context for future social interaction (Rintel, Mulholland \& Pittam, 2001). As the following excerpts from sessions one and two show, the participants' greetings were informal in nature:

(1) 1. Learner 3: hey

2. Learner 2: $\mathrm{Hi}$

3. Learner 2: hi KuraiCHO

4. Player 3: hello

(one line of text)

5. Learner 2: what level are you?

(one line of text)

6. Player 3: 10

7. Learner 2: 11

(2) 1. Learner 3: hi sammy

2. Player 4: hey hows it going?

3. Learner 3: fine

4. Learner 3: am trying to find the man

5. Learner 3: here he is

6. Player 4: what level are you

7. Learner 3: $7 \mathrm{u}$ ?

8. Player 4: 11 
As can be observed above, the participants in this study made informal greetings directed mainly at individual players. The use of general greetings, directed toward the group as a whole, were observed only infrequently. Researcher observation and transcript data confirmed that the use of greetings directed at individuals occurred across the four sessions, and that greetings were usually reciprocated. As the above data shows, the strategy of using informal greetings as a means of presenting a friendly, cooperative face to potential interlocutors appeared to be an effective means of signaling presence in the game, gaining attention from other players, and initiating interaction.

\subsection{Politeness: use of informal language, small talk, and humor}

A further type of positive politeness identified in the data was the extensive use of informal language. A significant feature of the interaction in this regard, was learners' use of slang and exclamations:

1. Player 1: watch this

2. Learner 4: cool

3. Learner 4: WOW!

4. Player 1: yeeeee

5. Learner 4: have never been here

6. Player 1: I have someone showed me

7. Learner 4: so I am lucky

8. Player 1: yep you found the right person

In the above excerpt drawn from the data collected in session two, learner four (accompanied by player one) enters a new area of the game. In line two, learner four expresses admiration for the new environment by use of the slang term cool. This is followed in the next line by an exclamation $W O W$ ! This presents a typical positive politeness strategy where the speaker signals an exaggerated sense of interest, in order to reduce social distance, and convey cooperation. In line seven, in another use of positive politeness, learner four praises player one by expressing admiration. As line eight shows, this effort is successful in both eliciting a positive reaction, and in enhancing social cohesion.

Another type of politeness used by the participants was small talk. This type of politeness has been identified as playing an important role in establishing, and maintaining, the collaborative interpersonal relationships, and social cohesion, necessary for successful communication in computer-based environments (Rintel \& Pittam, 1997). A typical instance of dialogue involving the use of this type of politeness took place in session three, where learner one's avatar was observed approaching another player having recently navigated to a new area in the game:

(4) 1. Learner 1: have you been into here?

2. Player 6: im sam 17 and I live in $\mathrm{Md}$

3. Learner 1: so young

4. Player 6: lol

5. Learner 1: I am Maryam, I live in Japan and I am 24

(two lines of text) 
6. Player 6: and you speak English that's pretty cool I wish I could speak Japanese

7. Learner 1: I can't speak Japanese either

8. Player 6: but you live there lol

9. Player 6: ?

10. Learner 1: I am not Japanese Sam

11. Player 6: oh ok

12. Learner 1: Yeah, but it is difficult lang, u know...

13. Player 6: that makes two of us and I noticed

In response to learner one's opening question, player six, in line two, provides personal information relating to age and location. There then unfolds a series of messages involving the exchange of interpersonal information. In line three, learner one comments on the apparent youth of her interlocutor and, in line five, provides information on her own location and age. This elicits a swift response from player six, who expresses admiration for learner one after only two lines of text scroll. In the following lines, learner one resolves the misunderstanding over her nationality. During this interaction, learner one expresses agreement and empathy for her fellow player in line twelve. In response, player six utilizes an utterance incorporating informal language, in which the use of the inclusive form us signals common identity and in-group status. On conclusion of this interchange, the above players were observed to engage together on a quest involving combat.

In addition to informal language and small talk, the participants utilized the positive politeness strategy of using humor as a means to facilitate ongoing interaction and to maintain collaborative interpersonal relationships. An instance of this type of politeness occurred in the early stages of session four:

1. Learner 1: hi DoberZlo

2. Learner 1: what level are $u$ ?

3. Player 2: jm 17 lev

4. Learner 1: Wow!

5. Learner 1: my level is $9:($

6. Player 2: ehh 100 lvl walk here quite often ; )

7. Player 2: you level is 9 (:)

8. Learner 1: yeah, but it is difficult to kill them

9. Learner 1: with my level

In excerpt five, learner one first greets player two and attempts to engage in small talk. This effort is successful as in line three player two responds appropriately. In line four, learner one displays admiration for their interlocutor's high level and status in the game through the use of an exclamation. In the next line, this participant makes a joke about their relatively low level in the game. This is followed by the use of an emoticon to signal unhappiness. This adaptive use of keyboard symbols may reflect the limitations of the 2D avatars used in Wonderland, which cannot display facial expressions. In the following two lines, player two responds by first acknowledging the joke and then continuing the humorous tone through the use of emoticons. In response, in the following lines, learner one returns the interaction to the quest at hand. 


\subsection{Politeness: leave-takings}

In the social interaction, positive politeness was also evident through often lengthy leave-takings. There was no evidence of the abrupt departures that are a feature of native speaker interaction in many computer-based communication environments such as chat rooms (Werry, 1996). A noteworthy feature of the interaction was that the learners engaged in somewhat lengthy leave-takings, as may be observed in the following data collected from session three:

1. Learner 3: good to be with you

2. Learner 3: hope we can make it next time too

3. Player 3: ok

4. Player 4: okay

5. Player 3: bye

6. Learner 3: good night!

7. Player 3:

8. Player 4: night

As excerpt six shows, learner three first signals in lines one and two that the interaction is coming to a close. There then unfolds in lines three through eight a prolonged series of messages between learner three and their interlocutor, where the interaction is brought to a close through a number of utterances that involve the appropriate use of positive politeness. This interaction shows how the learners and their interlocutors appeared to value their online relationships. Moreover, the data revealed that during leave-takings in each of the sessions, the learners and their fellow players went to considerable lengths to create a favorable impression, and signal a desire to achieve a harmonious parting.

\subsection{Establishment of intersubjectivity}

In sociocultural accounts of SLA, the establishment and maintenance of a shared communicative context for interaction, known as intersubjectivity, is a necessary precondition for learners to engage in collaborative TL use (Anton \& DiCamilla, 1998). The data indicated that the learners in this study established states of shared understanding regarding the quest at hand through two means. The first of these was their engagement in an activity known in Wonderland as making friends. As a MMORPG designed to facilitate social interaction, the Wonderland interface provides players with an onscreen icon that, when selected, enables an individual player to offer friendship. An instance of a learner establishing intersubjectivity through this mediational means of making friends occurred in session four:

(7) 1. Learner 2: wanna go to the cave?

2. Player 6: is kama cave?

3. Learner 2: I think so, I am not good at remembering the names

4. Player 6: be friend $\wedge \wedge$

5. Learner 2: yeah

6. Player 6: ${ }^{\wedge}$ 
7. Player 6: where do we go now?/

8. Learner 2: this way

In the above interaction, after clarifying the location of a venue for future interaction, player six offers friendship to learner two in line four. In the next line, learner two responds positively in the form of an informal utterance designed to signal acceptance of the offer and enthusiasm. Having established a friendship, player two first provides positive feedback in the form of an emoticon, and then moves the interaction forward with a question. The creation of the intersubjective state is confirmed in line eight with the learner's appropriate response to the interlocutor's question.

Another means to support the establishment of intersubjectivity identified in the data was the formation of teams. A significant design feature of Wonderland is that when undertaking certain quests, such as combat with monsters, players can make teams in order to improve their chances of leveling up in the game. An instance of team formation may be observed in the following interaction from session three:

1. Learner 3: $\mathrm{Hi}$

2. Player 7: hello

3. Learner 3: what level are you?

4. Player 7: ?

5. Learner 3: 11

6. Player 7: lucky

7. Learner 3: wanna go on a group?

8. Player 7: sure

9. Learner 3: good (one line of text)

10. Learner 3: do you see any question marks

11. Learner 3: on the map

12. Player 7: yea

13. Learner 3: Ok go for them

In excerpt eight, learner three first initiates contact with player seven through an exchange of greetings. Then there follows some small talk, and in line seven, learner three proposes to player seven that they form a team. As can be observed in the following line, this proposal is accepted. In the subsequent interaction intersubjectivity is established, as learner three drives the interaction forward with utterances that focus her interlocutor's attention on a forthcoming quest.

\subsection{Maintenance of intersubjectivity}

The literature on learner interaction emphasizes that states of intersubjectivity must be actively maintained for sustained interaction to occur (Anton \& DiCamilla, 1998). As has been observed in the literature on computer-based communication environments such as chat rooms (Darhower, 2002), maintaining intersubjectivity appears a challenging endeavor. Learners must monitor and make sense of scrolling text messages in real time, in a context where many of the cues inherent in face-to-face communicative contexts are either absent or greatly reduced. Analysis revealed that the participants 
were able to deal with the potentially challenging communication environment presented by Wonderland, and that they were able to engage in co-construction in the TL while successfully maintaining states of intersubjectivity over the sessions.

One means used by the learners to maintain states of intersubjectivity relating to game quests was the use of continuers, that is, utterances designed to signal attention and interest, and encourage an interlocutor to continue interaction (Foster \& Ohta, 2005). Analysis indicated that this type of utterance was a feature of learner linguistic output across the four sessions. A typical instance of the use of multiple continuers occurred in the early stages of session two:

(9) 1. Learner 2: what is the name of the place where this cave is in?

2. Learner 2: north island?

3. Player 5: yup

4. Player 5:

5. Learner 2: Lufftti is it north island here?

6. Player 5: yes! “

7. Learner 2: oh I mix up the names

8. Player 5: $\wedge \wedge$

9. Player 5: woo “

10. Player 5: amazing “

11. Learner 2: yeah

12. Learner 2: but I think nothing special to do here

13. Learner 2: right?

14. Player 5: yup

15. Player 5: so let

16. Player 5: Let's go! ${ }^{\wedge} \wedge$

17. Learner 2: ok!

In lines one and two, learner two uses continuers in the form of questions designed to signal attention and to clarify her location. These utterances are successful in encouraging her interlocutor to continue the interaction, and are met with an appropriate response in lines three and four. However, in the next line, learner two still appears unsure of her location and utilizes an additional continuer in the form of a confirmation request. In lines six through eleven, the confusion over location is resolved. In line twelve, learner two uses a continuer in the form of a statement that draws player five's attention to the limitations of their current location. This utterance is followed by another continuer in the form of a confirmation check, designed to signal interest and elicit feedback. As may be observed in the following lines, this effort is successful in securing a continuation of the interaction.

Another means which the participants utilized in order to maintain states of intersubjectivity during quests involved requests for assistance. The data contained evidence that when faced with a problem relating to technical aspects of their game play, the participants took an active role in requesting assistance from other players. An example of a request involving object manipulation occurred in the later stages of session one:

1. Learner 1: who took your tent?

2. Player 6: lyea 
3. Learner 1: how did she do it?

4. Player 6: lefft click it

5. Learner 1: great! I didn't know that

In excerpt ten, learner one attempts to establish the identity of the player responsible for moving a virtual object, in this case a tent that belonged to player six. When the identity of the culprit is revealed, learner one then requests assistance on how to carry out the same action. This request meets with a response in the following line, where player six provides feedback in the form of appropriate guidance. In the next line, learner one signals her gratitude for this information.

A further area where learners made requests for assistance involved the conduct of quests. A typical instance where a helpful response was provided may be observed in the following interaction:

1. Learner 2: Do you know where the pig is?

2. Player 7: idk if $\mathrm{u}$ can catch it but the pig pens are farther down

3. Learner 2: I see. Thank you. I'll try to catch it.

In excerpt eleven, learner two is engaged in a quest and requests assistance from another player in locating a virtual animal as part of this quest. Assistance is provided in the next line, whereupon the learner in response first signals understanding of the previous message, and then expresses thanks in an utterance that shows appropriate use of politeness strategies.

Another instance of the use of requests was found in an extension of the interaction between these participants:

4. Learner 2: could anyone help me with those highjackers?

5. Learner 2: How to defeat them for the second time?

6. Player 7: they are strong

7. Learner 2: yeah, they are

8. Learner 2: my level is 5 now

9. Player 7: hehe same as me

10. Learner 2: is it because of this that I can not defeat them?

11. Player 7: no... need help let's team up

12. Learner 2: wow! That's great

13. Player 7: let me get Roca first

14. Player 7: wait near them

15. Learner 2: ok

In lines four and five, learner two makes repeated requests for assistance on how to overcome a challenging situation that has arisen during a quest. These utterances meet with a prompt response in line six. In the next line, learner two first uses a statement to signal agreement, and interest, in player seven's previous comment. In the following line, this participant provides additional personal information in an attempt to elicit feedback and expand the interaction. As may be observed in line nine, this effort is successful in eliciting a response indicating agreement. In line ten, learner two returns to the problem at hand with a further request for assistance. As the remainder of the interaction shows, player seven provides immediate help, first 
by offering to form a team, and then by attempting to obtain the support of a higher level player.

In addition to requests for assistance, requests for clarification also occurred in the data, particularly when communication problems arose during the interaction. An instance of this phenomenon was identified in the second gaming session:

1. Learner 4: back to kelan viallge

2. Player 8: sorry if I lag my laptop keeps messing up

3. Learner 4: it's ok

4. Player 8: where are you chatting From?

5. Learner 4: what do you mean?

6. Player 8: sorry, I mean the country

7. Learner 4: I see I am in Japan now

8. Player 8: nice

In the first line of excerpt twelve, learner four invites player eight to return to a location in the game. In response, player eight initiates small talk focusing on a computer issue. During the unfolding interaction, a communication problem arises regarding player eight's utterance made in line four. In line five, learner four signals that a problem has arisen through the use of a clarification request. In response to this request for clarification, player eight provides additional information in the form of a rephrasing in line six. As the remainder of the interaction shows, this helpful feedback provided an effective means to resolve the issue.

\subsection{Participant attitudes}

In order to explore learner attitudes towards English language learning in a MMORPG, and to provide an additional source of data on the in-game interactions, participants were invited to take part in post-study oral interviews. The questions investigated were as follows:

1. Briefly describe your experiences playing Wonderland.

2. In your view what were the good points of playing the game?

3. Did you encounter any problems?

4. Do you think playing the game improved any of your English skills?

5. Is there anything else you would like to tell the researcher about your experiences participating in this project?

In these interviews, the participants drew attention to the difficulties they experienced in becoming familiar with the objectives of the game and with the required actions. This finding is consistent with previous research which identified a learning curve for many social MMORPGs (Peterson, 2011). They also emphasized the limitations of the ingame help features. In their feedback, the learners stated that:

Sometimes I got lost and don't know how to play.

I have met problems.

I got stuck.

Good introduction or explanation of the game should be provided, I think. 
The participants claimed that although the above issues were not fully resolved, they were largely overcome as the project progressed. Researcher observation confirmed this claim. In observing the interaction, the researcher noted that as the learners became more familiar with the specific features and culture of the game their degree of comfort appeared to increase.

The learners commented positively on other aspects of participation in this research. They claimed that the computer-based nature of the interaction in the MMORPG, in combination with the anonymity provided by the use of pseudonyms and avatars, helped to reduce anxiety and encouraged risk-taking when using the TL. In this context, a participant observed that:

I can be more brave when communicating with others than in real life.

Additional factors identified as valuable included the opportunities to engage in discourse management and to obtain fluency practice in English. In this context, a learner identified several beneficial aspects of taking part in real-time game play:

I found the game very helpful for speeding up my ability to make sentences and for learning a different type of English.

Another participant echoed these sentiments, claiming that playing the game provided exposure to types of English not normally encountered in regular language classes:

I learned new words like slang and informal English.

Participants also commented favorably on the opportunities provided to develop reading and vocabulary skills:

There are some new words I learned during chating with others.

I think we can develop our reading skills and vocabulary.

Two learners noted that the game provided exposure to a variety of new linguistic forms, and that the interaction was interesting:

I could learn a different type of English.

Ifound it quite interesting to learn using this game.

Learners also provided feedback on other aspects of participating in this research. They expressed the general view that interacting with players who were native speakers, though challenging at times, was particularly useful as a learning experience. Furthermore, three learners expressed the opinion that taking part in the project was a stimulating and enjoyable experience. These participants expressed largely positive views on the value of playing the game as a means of improving English skills. They also stated a desire to continue playing Wonderland in the future.

\section{Conclusions}

This study was subject to a number of limitations that should be borne in mind in any interpretation of findings. The number of participants was restricted. Due 
to institutional constraints, the researcher was unable to schedule any additional sessions. Moreover, the potential issues associated with learner self-reporting require acknowledgement. Care should therefore be taken when seeking to generalize the findings to other contexts. Although these factors may represent limitations, the data nonetheless provides a number of significant insights into the participants' linguistic and social interaction in the Wonderland MMORPG.

In the context of answering research question one, which aimed to chart the general nature of EFL learners' linguistic and social interaction in a MMORPG, analysis of transcript data and researcher observation shows that across the sessions the novicegamer learners effectively managed their real-time text-based interaction. They accomplished this considerable feat by utilizing a range of strategies associated with the development of sociolinguistic competence. Noteworthy features of the interaction in this regard involved the extensive and appropriate use of positive politeness in the form of greetings, leave-takings, informal language, small talk, and humor, as a means to build rapport. The frequent use of these types of politeness provided an effective means to support the formation of in-game relationships based on reciprocity and teamwork. These, in turn, facilitated the exchange of interpersonal information necessary to maintain collaborative relationships. The use of politeness appeared to prevent communication breakdowns in an environment where many social context cues are reduced, and supported the creation of the low stress atmosphere characterized by social cohesion that was observed during the sessions. In this regard, the analysis confirms findings reported in the literature on learner interaction in MMORPGs and other types of real-time CMC environments (Darhower, 2002; Thorne, 2008; Von Der Emde, Schneider \& Kötter, 2001).

Another significant feature of the interaction was that when participants made requests, helpful assistance was provided by other players in most cases. The data showed that the provision of assistance in combination with the use of continuers facilitated collaborative social interaction, co-construction, and provided an effective means to maintain states of intersubjectivity between the learners and their interlocutors during quests. Moreover, the scaffolding provided by peers in the game appears to have contributed to learners' production of coherent and appropriate TL over the sessions. Furthermore, it was found that the learners conducted their interaction exclusively in the TL and that contrary to findings reported elsewhere (Peterson, 2011) communication breakdowns were infrequent in this particular study. Although analysis reveals that collaborative social interaction was a distinguishing feature of the sessions the data contained little direct evidence for the operation of ZPDs. However, this finding is unsurprising as the study was limited in duration.

As for research question two, which was designed to reveal learner attitudes towards EFL learning in a MMORPG, the learners provided largely positive feedback mirroring, to a degree, findings reported in other research (Peterson, 2011, Reinders \& Wattana, 2011). Although the participants encountered problems during their game play, it was observed that their level of comfort increased as the project progressed. The learners asserted that the typed text and avatar-based nature of the interaction reduced anxiety and enhanced opportunities for risk-taking. Additional aspects of participation identified as beneficial included enhanced reading and writing skills. Learners also 
claimed that the interaction was interesting and enjoyable. The feedback further draws attention to an important issue, namely, the exposure to informal registers of English that are seldom encountered in conventional language classrooms. The literature on the use of MMORPGs in CALL emphasizes considerable opportunities for language development afforded by exposure to such digital vernaculars (Sykes, Reinhardt \& Thorne, 2010). However, researchers should also acknowledge that the incorporation of grammatically incorrect forms remains a potential risk for learner participation in MMORPGs as well as in other types of CMC environment where access is provided to native speaker interlocutors.

The data analyzed in this discussion has shed new light on EFL learners' linguistic and social interaction in a MMORPG. This exploratory research has established the viability of MMORPGs as venues for CALL projects involving intermediate level learners, and draws attention to potential advantages of interaction in a networkbased role-playing game. The findings suggest that from the perspective of sociocultural SLA, MMORPGs offer access to a context for TL use and social interaction that may eventually be conducive to language development. Moreover, this research also raises a number of issues of possible interest in future research. Additional studies of longer duration involving larger and more diverse groups are required, in order to further enhance understanding of learner TL use, and social interaction in the communication context provided by MMORPGs. Continuing exploration in this area offers the prospect of developing valuable new perspectives on how language development may be advanced through social interaction in MMORPGs.

\section{References}

Ang, C. S. and Zaphiris, P. (2006) Developing enjoyable second language learning software tools: A computer game paradigm. In: Zaphiris, P. and Zacharia, G. (eds.), User-centered computer aided language learning. New York: Idea Group, 1-22.

Anton, M. and DiCamilla, F. (1998) Socio-cognitive functions of L1 in collaborative interaction in the L2 classroom. Canadian Modern Language Review, 54(3): 314-342.

Atkinson, D. (2002) Towards a sociocognitive approach to second language acquistion. The Modern Language Journal, 86(5): 525-545.

Brown, P. and Levinson, S. (1987) Politeness: Some universals in language usage. Cambridge: Cambridge University Press.

Darhower, M. (2002) Interactional features of synchronous computer-mediated communication in the intermediate L2 class: A sociocultural case study. CALICO Journal, 19(2): 249-277.

Deutschmann, M., Panichi, L. and Molka-Danielsson, J. (2009) Designing oral participation in Second Life - a comparative study of two language proficiency courses. ReCALL, 21(2): 206-226.

Donaldson, R. P. and Kötter, M. (1999) Language learning in cyberspace: Teleporting the classroom into the target culture. CALICO Journal, 16(1): 531-557.

Firth, A. and Wagner, J. (2007) On discourse, communication, and (some) fundamental concepts in SLA research. The Modern Language Journal, 91(5): 757-772.

Foster, P. and Ohta, A. S. (2005) Negotiation for meaning and peer assistance in second language classrooms. Applied Linguistics, 26(3): 402-430.

Gee, J. P. (2005) Learning by design: Good video games as learning machines. E-Learning, 2(1): $5-16$. 
Jauregi, K., Canto, S., de Graff, R., Koenraad, T. and Moonen, M. (2011) Verbal interaction in Second Life: towards a pedagogic framework for task design. Computer Assisted Language Learning, 24(1): 77-101.

Lafford, B. A. (2007) Second language acquisition reconceptualized? the impact of Firth and Wagner (1997). The Modern Language Journal, 91(5): 735-756.

Lantolf, J. P. (2000) Sociocultural theory and second language learning. Oxford: Oxford University Press.

Lantolf, J. P. and Appel, G. (1994) Vygotskian approaches to second language research. Norwood, NJ: Ablex.

Lantolf, J. P. and Thorne, S. L. (2006) Sociocultural theory and the genesis of second language development. Oxford: Oxford University Press.

Lee, L. (2008) Focus-on-form through collaborative scaffolding in expert-to-novice online interaction. Language Learning \& Technology, 12(3): 53-72.

Nassaji, H. and Swain, M. (2000) A Vygotskian perspective on corrective feedback in L2: the effect of random versus negotiated help in the learning of English articles. Language Awareness, 9(1): 34-51.

Peterson, M. (2006) Learner interaction management in an avatar and chat-based virtual world. Computer Assisted Language Learning, 19(1): 79-103.

Peterson, M. (2010a) Massively multiplayer online role-playing games (MMORPGs) as arenas for language learning. Computer Assisted Language Learning, 23(5): 429-439.

Peterson, M. (2010b) The use of computerized games and simulations in computer-assisted language learning: A meta-analysis of research. Simulation \& Gaming: An Interdisciplinary Journal, 40(1): 863-885.

Peterson, M. (2011) Digital gaming and second language development: Japanese learners interactions in a MMORPG. Digital Culture \& Education, 3(1): 56-73.

Prensky, M. (2001) Digital game-based learning. St. Paul: Paragon House.

Purushotma, R., Thorne, S. and Wheatley, J. (2009) 10 Key Principles for Designing Video Games for Foreign Language Learning. http://lingualgames.wordpress.com/article/10-keyprinciples-for-designing-video-27mkxqba 7b13d-2/

Reinders, H. and Wattana, S. (2011) Learn English or die: The effects of digital games on interaction and willingness to communicate in a foreign language. Digital Culture \& Education, 3(1): 3-29.

Rintel, E. S. and Pittam, J. (1997) Strangers in a strange land: interaction management on Internet Relay Chat. Human Communication Research, 23(4): 507-534.

Rintel, E. S., Mulholland, J. and Pittam, J. (2001) First things first: Internet relay chat openings. Journal of Computer-Mediated Communication, 6(1). http://jcmc.indiana.edu/ vol6/issue3/rintel.html

Schwienhorst, K. (2002) Evaluating tandem language learning in the MOO: Discourse repair strategies in a bilingual Internet project. Computer Assisted Language Learning, 15(2): 135-145.

Steinkuehler, C. (2008) Massively multiplayer online games as an educational technology: An outline for research. Educational Technology, 48(1): 10-21.

Suh, S., Kim, S. W. and Kim, N. J. (2010) Effectiveness of MMORPG-based instruction in elementary English education in Korea. Journal of Computer Assisted Learning, 26(5): 370-378.

Sykes, J. M., Reinhardt, J. and Thorne, S. L. (2010) Multiuser digital games as sites for research and practice. In: Hult, F. M. (ed.), Directions and prospects for educational linguistics. Amsterdam: Springer, 117-135.

Thorne, S. L. (2008) Transcultural communication in open Internet environments and massively multiplayer online games. In: Magnan, S. (ed.), Mediating discourse online. Amsterdam: John Benjamins, 305-327. 
Thorne, S. L., Black, R. W. and Sykes, J. M. (2009) Second language use, socialization, and learning in Internet interest communities and online gaming. The Modern Language Journal, 93(s1): 802-821.

Von Der Emde, S., Schneider, J. and Kötter, M. (2001) Technically speaking: Transforming language learning through virtual learning environments (MOOs). The Modern language Journal, 85(2): 211-225.

Vygotsky, L. S. (1978) Mind in society: The development of higher psychological processes. Cambridge, MA: Harvard University Press.

Warner, C. N. (2004) It's just a game right? Types of play in foreign language CMC. Language Learning \& Technology, 8(2): 69-87.

Werry, C. (1996) Linguistic and interactional features of Internet relay chat. In: Herring, S. C. (ed.), Computer-mediated communication: linguistic, social and cross-cultural perspectives. Amsterdam: John Benjamins, 47-63.

Wertsch, J. (2007) Mediation. In: Daniels, H., Cole, M. and Wertsch, J. (eds.), The Cambridge companion to Vygotsky. Cambridge: Cambridge University Press, 178-192.

Zhao, Y. and Lai, C. (2009) Massively multi-player online role playing games (MMORPGS) and foreign language education. In: Ferdig, R. (ed.), Handbook of Research on Effective Electronic Gaming in Education. New York: IDEA Group, 402-421. 